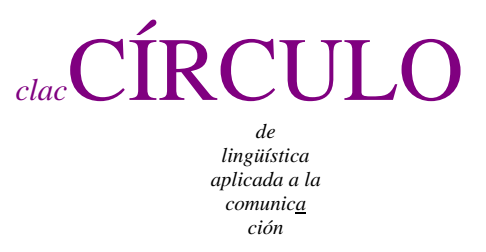

$67 / 2016$

\title{
LA METÁFORA TÉCNICA EN LA TRADUCCIÓN ESPAÑOL-INGLÉS DE LOS CAMPOS DE LA CEGUERA, EL CANSANCIO Y LA ESPIRITUALIDAD
}

\author{
Verónica Vivanco Cervero \\ Universidad Politécnica de Madrid \\ veronicacruz.vivanco en upm.es
}

\section{Resumen}

Este artículo analiza la correspondencia en la traducción español-inglés de tres campos de metáforas técnicas, las basadas en la ceguera, el cansancio y el mundo espiritual. Sin embargo, el análisis ha supuesto dejar de lado ciertas voces que bajo el aspecto de metáforas amparaban voces del lenguaje no desviado y, también, homonimias. El estudio revela una presencia mayor de la metáfora en la lengua española en los tres campos analizados, si bien el inglés también hace un uso abundante de ella. En el terreno intermedio entre la metáfora en una y otra lengua aparecen desequilibrios metafóricos entre ambos idiomas, muestra de una diferente percepción de la realidad. Finalmente, las conclusiones arrojan luz sobre el significado de las metáforas objeto de análisis: ciego, aturdimiento, fatiga, antidesvanecimiento, alma, ánima, ángeles, espectro, fantasma, mágico, postmortem, muerte, muerto, rosario, y Cruz de Malta.

Palabras clave: metáfora, lenguaje desviado, ametáfora, traducción

Verónica Vivanco Cervero. 2016.

La metáfora técnica en la traducción español-inglés de los campos de la ceguera, el cansancio y la espiritualidad.

Círculo de Lingüística Aplicada a la Comunicación 67, 343-360.

http://www.ucm.es/info/circulo/no67/vivanco.pdf

http://revistas.ucm.es/index.php/CLAC

http://dx.doi.org/10.5209/CLAC.53488

(C) 2016 Verónica Vivanco Cervero.

Círculo de Lingüística Aplicada a la Comunicación (clac)

Universidad Complutense de Madrid. ISSN 1576-4737. http://www.ucm.es/info/circulo 


\begin{abstract}
The correspondence in the Spanish-English translation is analyzed of three different fields of technical metaphors based upon blindness, fatigue, and the spiritual world. Some terms have been left aside that under the appearance of metaphors were mere samples of no-deviated language or cases of homonymy. The study reveals a higher presence of the metaphor in the Spanish language in the three fields of study, although the English language also shows a high index of metaphors. In between metaphors and non-metaphors, we find a lack of metaphorical equilibrium between Spanish and English in certain cases, which is a sign of the different perception of the reality. Finally, the conclusions shed light on the meaning of these words: blind, annoyance, fatigue, antifading, core, angels, espectrum, phantom, ghost, magic, postmortem, dead, etc.
\end{abstract}

Key words: metaphor, deviated language, non-metaphor, translation

Índice

1. Introducción 345

2. Método 348

3. Resultados 349

3.1. La ceguera 349

3.2. El cansancio 349

4. Discusión 355

4.1. Metáforas relativas a la ceguera 355

4.2. Metáforas relativas al agotamiento 356

4.3. Metáforas relativas a lo espiritual 356

5. Conclusiones 357

Abreviaturas utilizadas 359

Bibliografía 359 


\section{Introducción}

La lexicografía es la rama de la lingüística aplicada, como indica Rey (1995:13), encargada del diseño y elaboración de los diccionarios. Un diccionario es, por lo tanto, la mejor muestra de la observación de la realidad y de cómo esta se plasma en palabras y términos y de especialidad. La universalidad del conocimiento procede de la observación integral de la naturaleza y de las derivaciones que fabrica el ser humano partiendo de esta. En las páginas de la obra lexicográfica fluye cualquiera de los principios que forman parte del conocimiento de la humanidad. Así, los usos lingüísticos con los que bautizamos los diferentes conceptos demuestran cómo percibimos la realidad, y, en concreto las metáforas, se convierten en la mejor demostración del engranaje cognitivo que fluye por los diccionarios.

La metáfora muestra nuestros conocimientos y opiniones sobre la realidad. Por lo tanto, el lenguaje desviado mimetiza y se acopla sobre el real, precisamente porque el concepto surge de una visión derivada de otro concepto, similar y primigenio. Así, el significado metafórico siempre surge del ametafórico, del real, debido a la capacidad de la morfología en cuestión de generar nuevos significados. De este modo, el grado de uso viene dado por la polivalencia semántica y por el enfoque común de un gran grupo de usuarios de un idioma. Sin embargo, los usuarios de diferentes idiomas no tienen por qué enfocar los conceptos de modo homogéneo. Así, lo que resulta transparente, claro y evidente para un sistema lingüístico puede no serlo para otro. La apreciación de un parecido entre conceptos u objetos, la perspectiva de un enfoque dual y contrastivo, porque se trata de entidades diferentes, pero vinculado por una cierta semejanza, emana y fluye hacia la semántica, quien ejerce que al antiguo. Cuando las lenguas se mueven de modo simétrico, el proceso de traducción no muestra problemática alguna, pero el trasvase se complica cuando dos conceptos diferenciados se muestran independientes en una lengua y vinculados en la otra. Así, si bien la metáfora tiende puentes entre realidades y conceptos diversos, lo que ayuda a engarzar objetos distintos en una sola aproximación o ventana al mundo, también tiene la ambivalencia de la simplicidad. Esto conlleva aspectos positivos, como la facilidad de comprensión y retención mental, la economía y reciclaje morfológico de una sola voz, y, el ahorro de espacio y papel en un diccionario, que, en una única entrada, da cabida a una gran cantidad de opciones traductológicas. 
Como apunta Bustos (2000:12), la metáfora formula preguntas sobre la realidad y transmite nuestros conocimientos y opiniones. El enfoque cognitivo, que une lengua y pensamiento (Lakoff 1987; Langacker 1987 y 1991) refleja la mentalidad de los usuarios. Lakoff y Johnson (1980) trataron de captar los esquemas mentales que subyacen al pensamiento, argumentando que el sistema conceptual tiene una naturaleza metafórica. Así contemplamos un dominio de la experiencia desde otro dominio, porque el primero existía antes y nos resulta más fácil de comprender. Por otro lado, Rorty (1989: 18) indica que el uso de la metáfora tiene un fin discursivo y actúa como señuelo para captar la atención, ya que introducir una metáfora en un texto equivale a utilizar cursiva o ilustraciones. Numerosos autores se ocupan en la actualidad del estudio y la enseñanza de la adquisición de la metáfora (Batlle 2014, Boers 2013, Cheikh-Kahmis 2013, Ibarretxe-Antuñano 2012 y Vidiella 2012) por ser el tema central del cognitivismo.

La metáfora es un préstamo léxico-semántico, ya que supone la adopción de una morfología preexistente, perteneciente a un significado primigenio y fértil que ha originado nuevas derivaciones semánticas basadas en una semejanza mínima entre dos objetos. Para Lakoff (1987), las metáforas son figuras conceptuales que sirven de vehículo para conceptualizar con términos concretos zonas abstractas de la experiencia, pero, como veremos más adelante, las metáforas se aplican también a zonas tangibles y concretas del conocimiento técnico.

El flujo entre el lenguaje general y los lenguajes de especialidad es inevitable y saludable (Pérez Bouza, 1998:397), por más que obre en contra de la deseada monosemia. Sin embargo, el que muchas de las denominaciones del ámbito científico y técnico se acompañen de una cadena de significados, porque las lenguas genéricas y las de especialidad están en mutuo contacto, es muestra de interacción y de enriquecimiento mutuo, pero también de polivalencia semántica, lo que no deja de ser un lastre para las lenguas de especialidad. Es precisamente, la semejanza desde cualquier perspectiva entre el entorno natural y el técnico lo que propicia el enfoque metafórico, compartiendo, así, morfología y semántica en un engranaje que encastra realidad y lingüística. 
La metáfora técnica no intenta sorprender o crear belleza, como sucede con la literaria. El fin de los usos técnicos es, simplemente, contribuir a explicar, con la máxima claridad posible, el entorno que nos rodea. Así, la más mínima similitud sirve de base para aprovechar la morfología en la que se encarnan los conceptos. El comportamiento de la metáfora en el léxico de especialidad es muestra de humanismo, del enraizarse en la simbología de la naturaleza y el entorno del ser humano.

En los lenguajes técnicos la influencia del inglés ha hecho que las lenguas receptoras de las acuñaciones que tienen lugar en países anglófonos, muestren patrones universales en sus tecnolectos. Así, las distintas comunidades profesionales de científicos e ingenieros parecen emplear una especie de lenguaje casi universal, en el que el léxico y, muy a menudo, la sintaxis se acomoda a los esquemas de la actual lengua franca de la ciencia y la tecnología. Sin embargo, la universalidad de los lenguajes técnicos, si bien suele obrar en contra de la pureza de los distintos idiomas, conlleva alguna ventaja importante, como es la creación de una jerga universal que trasciende fronteras y lenguas.

La infiltración de voces anglosajonas obedece a la lentitud de los países receptores en la acuñación de una terminología propia que bautice mecanismos y conceptos. Sin embargo, quien inventa el objeto, la fórmula o la teoría se convierte también el denominador del producto inventado. Además, a este respecto, la ciencia y la tecnología son disciplinas universales, ya que trascienden fronteras para avanzar en el conocimiento y simplificar las condiciones de vida del ser humano, cualquiera que sea su lengua, raza o credo.

El carácter universal de los avances de la humanidad causa que el concepto reciba una denominación que pasa de lo nacional a lo internacional. A este respecto, no conviene olvidar que no todo lo que se acuña en el mundo anglosajón pertenece al fruto de la investigación de nativos, sino a científicos e ingenieros de múltiples procedencias que encuentran en el extranjero mayores facilidades, de cualquier índole, para llevar a cabo sus estudios.

Como apunta Comellas (2007) “Traducir nos ayuda a comprender al otro y también a nosotros mismos, a mirarnos con nuevos ojos, a mirarnos desde el otro”; pero ¿de qué modo reflejarnos en el otro? es la cuestión que plantea Fischer (2008) como sigue "La pregunta de si 
hay que acercarle al lector del texto de llegada la cultura del texto de partida o bien acercar este a la cultura ajena es tan vieja como el oficio de la traducción mismo.”

De lo anterior, resulta evidente que el peso de las diferencias culturales en los textos literarios y humanistas es muy grande, pero no lo es tanto que estas ejerzan tal influencia en textos científicos, puesto que estos han de guiarse por la asepsia y por lo que es comprobable desde el punto de vista empírico y universal. Sin embargo, la globalización, como muestra de transculturalidad e interculturidad, ejerce tal influencia en la difusión y asimilación de conocimiento que las distintas peculiaridades culturales y sociológicas de los diferentes idiomas parecen irse difuminando a medida que avanza la sociedad del conocimiento y de la información.

\section{Método}

El léxico técnico del español y el inglés muestran una alta presencia metafórica porque la dilatada trayectoria de sus disciplinas convierte la premisa de la monosemia, máxime si se tiene en cuenta el flujo entre los distintos lenguajes de especialidad, en un requisito difícil de cumplir. Por dicho motivo, el objetivo de este trabajo es observar y mensurar la interacción entre el inglés y el español en la polisemia, y más en concreto, en el léxico metafórico usado en la ciencia y la tecnología. Para ello se han escogido metáforas referidas a la ceguera, el agotamiento y el mundo espiritual.

Para comprobar la paridad o disparidad metafórica en ambos idiomas nos fijaremos solo en la correspondencia traductológica de la forma que alude a la metáfora en sí, con independencia de que actúe dentro de un compuesto. Es decir, si el compuesto es brida ciega/blind flange nos fijaremos solo en el adjetivo metafórico para establecer la paridad o disparidad metafórica.

Otro aspecto a discernir será el de si todo lo que parece metáfora, realmente lo es, por tener un sentido figurado. Sin embargo, como toda morfología parte de un sentido real hasta que, con el tiempo y el uso, se metaforiza, el escrutinio del significado real de la voz será el que dé la pauta sobre si una voz en cuestión se trata de un desvío de la realidad o no. Además de tener una misma morfología un significado real y otro desviado, también puede presentar dos entradas inconexas semánticamente, con lo que también se atenderá al aspecto de la homonimia escondida tras una apariencia de metáfora. 


\section{Resultados}

\subsection{La ceguera}

Con respecto al adjetivo ciego en el DRAE, la primera acepción se refiere a la ausencia de vista, y, de esta, derivan los significados técnicos que aparecen en las posiciones quinta para referirse a un vano o conducto obstruido o tapiado. El mismo sentido aparece en la posición sexta cuando se refiere a un muro o una pared sin aberturas.

Así, en electrónica, encontramos la forma tapa ciega (blank cover), con una ruptura formal con respecto a la forma inglesa puesto que esta alude a una cubierta en blanco, vacía o virgen. En aeronáutica, brida ciega (blind flange) presenta simetría con respecto a la traducción del adjetivo pero no del sustantivo que lo acompaña puesto que flange en inglés no es una brida sino un reborde. Sin embargo, en este estudio nos fijaremos solo en la correspondencia traductológica de la forma que alude a la ausencia de sentidos. En contraste, vuelo a ciegas (blind flying), el que se realiza sin ayudas a la navegación, presenta una equivalencia total entre el pare español y el inglés. Dentro del campo de la mecánica, agujero ciego (DT) muestra una correspondencia total con la forma inglesa (blind hole). En contraste, la forma tuerca ciega (bonnet nut) pasa de la alusión a la ausencia de sentidos en español a la referencia a los sombreros. En minería, galería ciega supone una equivalencia simétrica del inglés (blind level), mientras que en la técnica de las herramientas se emplea el término llave ciega (key blank), con una nueva aparición de la forma blank para referirse a lo que está virgen, en este caso a la llave predentada.

\subsection{El cansancio}

En cuanto a las alusiones al agotamiento en tecnología encontramos muy diversas formas:

Algunas de ellas son falsas apariencias metafóricas, como ocurre con la forma agotamiento, como podemos ver en las siguientes líneas. En informática la forma zona de agotamiento se traduce por depletion layer, pero, sin embargo esta alude a una capa, más que a una zona. Además, el término agotamiento se refiere en ambos idiomas a la merma o disminución en términos de abundancia de existencias o económicos, puesto 
que la economía es la administración de los recursos escasos. Este agotamiento técnico se refiere a la escasez de recursos, como indica el DPLEI, y no al cansancio físico. Sin embargo, que la forma agotamiento no sea una metáfora significa que su sentido es real y no figurado, puesto que el agotamiento de existencias como falta o carencia de recursos se enlaza con el agotamiento físico en el sentido de carencia de energía.

En radiocomunicaciones, perturbación accidental se convierte en accidental jamming con lo que existe una diferencia con el inglés que alude a un atasco en lugar de a un cambio en la forma o actitud, como hace el español. Dicho cambio procede de interferencias en los sistemas o componentes eléctricos. En acústica, blur se traduce también por perturbación, aunque la forma inglesa se acerca más al sentido de difuminación. Sin embargo, hablar de perturbaciones en tecnología es un campo colateral al de la fatiga de los sistemas y no inherente a él de por sí.

El vocabulario técnico también refleja enfermedades profesionales, como ocurre en el campo de la telegrafía. Así, este tipo de trabajo, igual que el de otros profesionales como costureras, escritores, usuarios de ordenadores, etc produce un tipo de contractura conocida como espasmo del telegrafista que se dirige, en inglés, hacia la forma calambre (operator's cramp), y, aquí, aunque la correspondencia no sea total sí nos encontramos dentro un mismo campo, el del dolor y un sentido ametafórico.

Formas metafóricas sí son las que, por ejemplo, se dan en acústica, con la voz aturdimiento, para referirse a una zona de ruido estridente que se traduce por enojo (annoyance), con lo que la referencia cambia del cansancio al estado de enfado. El aturdimiento es, no obstante, también una perturbación de un estado. Antidesvanecimiento en el vocabulario de la radio se traduce literalmente por antifading, con lo que la simetría es perfecta en ambas formas. Su antónimo, el desvanecimiento también consiste en una perturbación de la conciencia, con lo que las últimas formas analizadas se relacionan entre sí.

El DST distingue entre la fatiga tomada en el sentido del cansancio, que responde al ámbito de los seres vivos, y la fatiga como debilitamiento, fallo o simple desgaste, sentido que enlaza con el ámbito de los materiales y la maquinaria técnica. Este segundo tipo de fatiga toma causa por consecuencia, ya que es el cansancio de cualquier tipo el que produce el fallo o desgaste. Así, el uso excesivo de un dispositivo conlleva a los 
fallos, y la exposición a la intemperie de cualquier material aboca a su desgaste y rotura. Del mismo modo, fatiga de un dieléctrico es un calco paronímico del inglés dielectric fatigue.

\subsection{La espiritualidad}

Existen una gran variedad de metáforas técnicas que aluden al mundo espiritual, por ser una parte inherente al ser humano. Sin embargo, en este campo también aparecen voces ametafóricas, aunque a primera vista no den tal impresión. A una unión de espigas (cogging), se la llama mortaja o filete en carpintería; mortajado (grooving), al ranurado; y, en mecánica, mortise gear es un dispositivo para mortajar o un engranaje de dientes postizos. En este caso, la referencia al mundo espiritual, de los muertos, resulta una mera apariencia, puesto que el DRAE muestra dos entradas independientes, una para el vestido del muerto, y, otra, para indicar el hueco que se hace en un objeto y encastrarle en otro. Esta doble entrada señala el carácter homónimo de ambas voces, que parecen una misma palabra sin serlo, solo por una mera coincidencia morfológica. La homonimia es causante de problemas de todo tipo, incluyendo los referidos a explicaciones ambiguas. La definición 1 a del Webster dice de homonymous: "having two or more different significations.” Esta definición induce a pensar en la polisemia, ya que esta conduce a significados variados, si bien unidos semánticamente, a diferencia de lo que ocurre con la polisemia. Asimismo, se empareja a la homonimia con la polisemia cuando en realidad esta debería estudiarse en contraste con la monosemia. En nuestra opinión, mientras que la homonimia es un recurso morfosemántico, centrados en aspectos formales y de sentido, la polisemia es un recurso semántico, ya que enfoca significados y no formas. Etimológicamente la palabra homonimia quiere decir igual nombre, sin hacer alusión alguna al aspecto semántico, mientras que la denominación polisemia se centra en los significados.

En un cable, el núcleo (cable core) es la parte central. Aquí vemos la disfunción traductológica puesto que lo que el inglés llama corazón, el español lo conoce por núcleo. Según el DUE en su acepción cuarta el término se usa para referirse a algo que está en el centro o la parte más íntima de un objeto. Por lo tanto el término corazón tiene que ver o con lo afectivo o con lo interno a un objeto. Sin embargo, la voz core del 
inglés si bien parte del equivalente latino para la palabra corazón, ha quedado relegado a los usos técnicos, con lo que, en inglés, no se puede decir que este tipo de corazón mantenga relación con el mundo de los sentimientos o del espíritu. Se trata, en consecuencia, de un caso de restricción semántica.

Ya pasando al campo de las metáforas técnicas de base espiritual o religiosa, la forma alma representa la interioridad de un elemento, al hueco dentro de él o al material que se mete dentro para dar mayor consistencia a la interioridad; como en hilo de contacto de aluminio con alma de acero (steel-aluminum contact wire) y picado en el ánima para referirse a cañones se traduce por pitted gun. El adjetivo picado se refiere a todos los restos de la corrosión y la pólvora, pero el inglés no alude al exterior o al interior del arma. Ánima se toma como sinónimo de la voz alma, tanto en el vocabulario general como en el léxico técnico.

Según el DRAE, en su acepción 10, el alma es lo que "se mete en el hueco de algunas piezas de poca consistencia para darles fuerza y solidez, como el palo que se mete en hacheros de metal, varas de palio, etc.” Sin embargo, la acepción 11 habla en sentido contrario: 11. f. Hueco o parte vana de algunas cosas, y especialmente, ánima del cañón. En radiocomunicaciones, ángeles (angels) son los ecos parásitos que se ven en las pantallas de los radares. En este caso la terminología de referencia es homóloga en ambos idiomas. Como indica el DT los ángeles se atribuyen a las interferencias que causan los pájaros.

En física se emplea muy a menudo la palabra espectro para denominar a la "serie de las frecuencias de una radiación dispersada que resultan en orden creciente” (DUE), como en el compuesto espectro similar al de la luz (artificial daylight) y en espectro audible (audible spectrum). Espectro, en física, se refiere a la distribución de energía de las ondas. En el caso de la química, espectro se refiere a los registros o imágenes de la energía de un objeto. En este campo, ether spectrum se conoce como espectro etéreo, por lo que comprobamos que el inglés suele ir a la par que el español en el campo de las radiaciones y de la química.

También observamos el uso de la voz fantasma en el léxico técnico: double phantom circuit/double ghost circuit/superphantom circuit en telefonía, se refiere al circuito fantasma doble, como indica el DITCA. Un circuito fantasma es en el que se utiliza los 
cables de un sistema para conducir señales a otro. Ghost beacon, en ayudas a la navegación, designa a un radiofaro fantasma o ficticio, porque, a veces se puede ver una imagen duplicada.

En la radio, la forma T mágica (magic tee) designa al acoplo de las guías de ondas, que tiene una forma similar a la letra t. En electrónica, al indicador de sintonía de rayos catódicos, se le conoce, de modo coloquial, como ojo mágico, por tener una apariencia similar a la de un ojo. El inglés también usa tanto la forma magic eye como cathode ray tuning indicator, con lo que nos encontramos ante un caso más de paridad traductológica.

En informática encontramos el adjetivo postmortem que designa a una rutina de depuración o postmortem dump, que se conoce como vuelco póstumo o análisis postmortem. Esta forma ha pasado de la medicina al vocabulario general y al técnico, en cuyo caso se refiere a un proceso de depuración que pertenece al análisis forense informático para determinar los efectos de una intrusión en un sistema. Por lo tanto, comprobamos cómo el español y el inglés van a la par en la referencia terminológica, más que nada porque el español calca del inglés.

En los semiconductores, el corte en el flujo se designa muerte repentina (sudden death), con otra coincidencia traductológica entre ambos idiomas. Muerto (dead), como indica el DC, se refiere también a los circuitos eléctricos que tienen una toma de tierra. La voz muerto ha pasado también al vocabulario naval, donde forma múltiples compuestos: muerto o boya de anclaje (deadman), en cuyo caso se trataría de una boya más pequeña que la del inglés mooring buoy; también se habla del muerto de amarre (anchor buoy) y del muerto de dos anclas (two-leg mooring). En todos estos casos el sema de muerto implica en exclusiva inactividad o situación fija del ancla, pero no se refiere nunca a la pérdida de vida. Observamos que el español se mueve entre las formas muerto y boya. El inglés, en contraste suele utilizar una tercera alternativa, mooring. Hacemos notar el sentido opuesto de las voces muerto y boya:

La voz muerto se relaciona con lo falto de movimiento, lo estático, lo parado y lo que ha perdido el aliento de la vida. Es un término de connotaciones negativas. 
La voz boya se refiere a lo que flota, a lo que se mantiene a salvo a pesar de las circunstancias adversas, y, así, estar boyante significa que la situación, sobre todo económica es de bienestar y desahogo.

En radiocomunicaciones el significado de muerto varía y se refiere a un sector muerto (blind sector) que designa a la sombra de una pantalla de radar producida por chimeneas o mástiles de barcos cercanos a la antena, por lo que el radar no puede vigilarla, y de ahí la referencia a la muerte, por no ser una zona con la que se pueda trabajar. El inglés, en contraste, acude a otra metáfora, la de la ceguera, que también tiene su razonamiento lógico puesto que el sector no se puede vigilar por el radar por estar tapado por una proyección de sombras. Sin embargo, una pega que se le puede achacar a este compuesto es que el sector en sí no es ciego por no ver, sino por no ser visto, con lo que apreciamos una traslación del campo de la ausencia de sentidos de un objeto a otro: se le achaca al sector, la ceguera del radar. Por lo tanto, en este caso, la metáfora española parece mucho más acertada.

En el ámbito de las soldaduras se emplea la forma rosario para designar a una cadena de estas (weld of beads) - Sin embargo, como indica el DETT, la forma weld también equivale al significado de gualda.-, y en meteorología, se habla de relámpagos rosario (pearl lightning). Este tiene forma esférica y encadenada, y, de ahí, su nombre. La forma rosario pasa del vocabulario católico en el que define a un conjunto de oraciones $\mathrm{y}$ al instrumento con el que se rezan, lo que nos lleva al sentido de encadenamiento, cascada o racimo. El inglés, sin embargo, alude a las cuentas, que son cada una de las unidades que forma un rosario o un collar, por lo que la voz cuenta no tiene en sí misma connotaciones religiosas. Intermittent sprocket es, en mecánica, una rueda dentada que también se llama a veces cruz de Malta, porque el bosquejo de la rueda puede recordar ligeramente a la Cruz de la Orden de Malta. 


\section{Discusión}

\subsection{Metáforas relativas a la ceguera}

Tabla 1

\begin{tabular}{|l|l|l|}
\hline Español & Inglés & Correspondencia \\
\hline Tapa ciega & Blank cover & Ametáfora del inglés \\
\hline Brida ciega & Blind flange & Metáfora simétrica \\
\hline Vuelo a ciegas & Blind flying & Metáfora simétrica \\
\hline Agujero ciego & Blind hole & Metáfora simétrica \\
\hline Tuerca ciega & Bonnet nut & Metáfora asimétrica \\
\hline Galería ciega & Blind level & Metáfora simétrica \\
\hline Llave ciega & Key blank & Ametáfora del inglés \\
\hline
\end{tabular}

En el cuadro 1 observamos que de un total de 7 metáforas relacionadas con la ausencia de vista, 4 son simétricas entre el español y el inglés, mientras que solo 1 es asimétrica, porque, mientras que el español enfoca la ceguera, el inglés apunta hacia la sombrerería. Sin embargo, lo anterior no debe resultar chocante puesto que la tuerca ciega es la que no tiene el orificio libre, por estar taponado por una especie de caperuza o cobertor metálico. Se trata, en realidad, de dos modos de percibir una misma realidad. Por otro lado, el cuadro 1 muestra que existen dos metáforas en español que en inglés no se muestran como voces del lenguaje figurado, por lo que el inglés parece una lengua más realista, puesto que es más clarificador hablar de objetos vírgenes o sin manipular (blank) que hacerlo de objetos ciegos, puesto que realmente no lo están. Sin embargo, la visión metafórica del español parece acercar más la tecnología a la vida cotidiana.

De lo dicho se muestra que el 57,1 \% de las formas analizadas muestra una coincidencia simétrica en el trasvase metafórico entre el español y el inglés. Solo un mínimo 14,2 \% muestra la falta de paridad perfecta entre las metáforas técnicas del español y del inglés, y, por último, un porcentaje de un 28,4 muestra el uso metafórico exclusivo del español frente a la ametáfora del inglés. 
4.2. Metáforas relativas al agotamiento

Tabla 2

\begin{tabular}{|l|l|l|}
\hline Español & Inglés & Correspondencia \\
\hline aturdimiento & annoyance & Metáfora asimétrica \\
\hline antidesvanecimiento & antifading & Metáfora simétrica \\
\hline Fatiga del dieléctrico & Dielectric fatigue & Metáfora simétrica \\
\hline
\end{tabular}

En la tabla 2 observamos que, de un total de 3 metáforas relativas al cansancio en la técnica, dos son simétricas y 1, si bien también constituye un uso metafórico en ambos idiomas, es asimétrica puesto que mientras el español acude a la voz aturdimiento, el inglés lo hace hacia el enojo. De todo lo anterior se observa que en el campo del cansancio, existe una casación español-inglés que se eleva al 66,6 \% de los casos. En contraste, un porcentaje del 33’3 muestra un desequilibrio en los campos de referencia.

\subsection{Metáforas relativas a lo espiritual}

Tabla 3

\begin{tabular}{|l|l|l|}
\hline Español & Inglés & Correspondencia \\
\hline $\begin{array}{l}\text { Hilo de contacto de aluminio } \\
\text { con alma de acero }\end{array}$ & Steel aluminum contact wire & Ametáfora del inglés \\
\hline Picado en el ánima & Pitted gun & Ametáfora del inglés \\
\hline Ángeles & Angels & Metáfora simétrica \\
\hline Espectro similar al de la luz & Artificial daylight & Ametáfora del inglés \\
\hline Espectro audible & Audible spectrum & Metáfora simétrica \\
\hline Espectro etéreo & Ether spectrum & Metáfora simétrica \\
\hline Circuito fantasma & Phantom circuit & Metáfora simétrica \\
\hline Radiofaro fantasma & Ghost beacon & Metáfora simétrica \\
\hline T mágica & Magic Tee & Metáfora simétrica \\
\hline Ojo mágico & Magic eye & Metáfora simétrica \\
\hline Análisis postmortem & Postmortem dump & Metáfora simétrica \\
\hline Muerte repentina & Sudden death & Metáfora simétrica \\
\hline muerto & deadman & Metáfora simétrica \\
\hline Muerto de amarre & Anchor buoy & Ametáfora del inglés \\
\hline
\end{tabular}




\begin{tabular}{|l|l|l|}
\hline Muerto de dos anclas & Two-leg mooring & Ametáfora del inglés \\
\hline Sector muerto & Blind sector & Metáfora asimétrica \\
\hline Rosario & Weld of beads & Ametáfora del inglés \\
\hline Relámpago rosario & Pearl lightning & Metáfora asimétrica \\
\hline Cruz de Malta & Intermittent sprocket & Metáfora asimétrica \\
\hline
\end{tabular}

En el cuadro 3 para metáforas técnicas relativas a lo espiritual, encontramos que la mayor parte de ellas son simetrías perfectas entre el español y el inglés: de un total de 19 metáforas, 10 son acoplamientos traductológicos, lo que hace una 52,6 de equivalencias plenas. El número de asimetrías metafóricas asciende solo a tres casos: muerto/blind, rosario/pearl y cruz de Malta/sprocket, formas que, no obstante, mantienen entre sí cierta relación: de la ausencia de sentidos a la de solo uno, de un encadenamiento a la unidad, y de una cruz al esquema de una rueda. Estos 3 casos suponen solo un 15,7 porcentual de la totalidad. Finalmente, los ejemplos de ametáforas suben a 6 casos, lo que hace un porcentaje de un 31,4. Cabe señalar aquí que las ametáforas lo son solo por parte del inglés y no de la lengua española, que en todos los casos parte de ellas (muerto, rosario).

\section{Conclusiones}

Dejando de lado las falsas metáforas que se presentan en todos los diccionarios y que responden o bien a voces no desviadas semánticamente o a homonimias puras, el estudio de las metáforas técnicas revela una mayor abundancia en la lengua española en cualquiera de los 3 campos analizados.

En el primer campo, la ceguera, el 57,1 de las voces responden a paridad traductológica; un 14'2, a disparidad, manteniéndose no obstante ambos idiomas dentro de lo metafórico; y, un 28,4 muestra la falta de correspondencia metafórica del inglés.

Estas metáforas relativas a la ausencia de vista se relacionan con los siguientes significados:

Ciego: en blanco, vacío, virgen/ taponado, sin salida/ sin ayudas a la navegación 
En el segundo campo, el agotamiento, el 66,6 de las morfologías corresponden a una perfecta simetría de usos, mientras que el 33,3 muestra un desvío metafórico puesto que lo que para el español es aturdimiento, para el inglés es enojo.

Las metáforas relativas al cansancio se relacionan con los siguientes sentidos técnicos:

Aturdimiento: ruido estridente

Fatiga: debilitamiento, fallo, desgaste

Antidesvanecimiento: mecanismo para reducir la fatiga o el colapso de un sistema.

En el tercer campo, las metáforas relativas al ámbito espiritual muestran un 52,6 de correferencias traductológicas, mientras que un 15,7 muestran una dispersión en el uso de la metáfora. Sin embargo, un 31,4 por ciento de las voces muestran una escapada del uso metafórico por parte del inglés. Llama la atención en este apartado que en el caso del compuesto sector muerto el inglés alude a la ceguera y se refiere a tal concepto con la forma blind sector, para referirse a la zona que no se deja ver con claridad por la proyección de sombras.

Las metáforas relativas a lo espiritual se relacionan con los siguientes significados:

Alma/ánima: interioridad de un elemento

Ángeles: ecos

Espectro: emisión de frecuencias

Fantasma: intermediario de comunicación/aparición de imágenes duplicadas

Mágico: acoplamiento de ondas

Postmortem: análisis de depuración

Muerte: corte de flujo

Muerto: toma a tierra/inactividad de un elemento marítimo

Rosario: encadenamiento

Cruz de Malta: bosquejo de una rueda

El inglés como una lengua más aséptica y realista, que, quizás, enlaza menos los diferentes conceptos de la realidad cotidiana. El inglés se muestra como una lengua que, 
si posee un término real y no desviado, para mostrar un concepto, hace uso de él, a pesar de que sea menos evocador, pintoresco o llamativo. Sin embargo, no podemos evitar comprobar el enorme anclaje del fenómeno semántico de la metáfora en ambos idiomas.

\author{
Abreviaturas utilizadas \\ DC Diccionario de las Ciencias \\ DETT Diccionario Enciclopédico de Términos Técnicos \\ DITCA Diccionario de Informática, Telecomunicaciones y Ciencias Afines \\ DPLEI Diccionario Politécnico de las Lenguas Española e Inglesa \\ DRAE Diccionario de la Real Academia de la Lengua Española \\ DST Dictionary of Science and Technology \\ DT Diccionario Tecnológico
}

DUE Diccionario de Uso del Español

Bibliografía

Batlle, J. (2014). En el amor y en la guerra: una unidad didáctica para el desarrollo de la competencia metafórica. Jornadas pedagógicas de ELE. Valencia: Educaspain.

Boers, F. (2013). Cognitive linguistic approaches to teaching vocabulary: assessment and integration. Language Teaching, 46, 208-224.

Bustos, Eduardo. La metáfora. Ensayos interdisciplinares. Madrid: Fondo de Cultura Económica, 2000.

Cheikh-Kahmis, F. (2013). Lingüística cognitiva aplicada a la enseñanza del léxico en segundas lenguas. Las colocaciones en clase de ELE. Universidad a distancia. RedEle http://www.mecd.gob.es/dctm/redele/Material-RedEle/Biblioteca/2013bv-14/2013_BV_14_24CHEIKHKHAMIS.pdf?documentId=0901e72b8172935e

Comellas, P. (2007). La traducción de la cultura. Cultura e intercultura. Edinumen. 
Fischer, Martin B. (acceso 2015) Diferencias culturales reflejadas en la traducción de la literatura infantil y juvenil. https://pendientedemigracion.ucm.es/info/especulo/ ele/vigo.html

Ibarretxe-Antuñano, I. y Valenzuela, J. (2012). Lingüística cognitiva. Barcelona: Anthropos.

Lakoff, G. (1987). Women, Fire and Dangerous Things: What Categories Reveal about the Mind. Chicago: The University of Chicago Press.

Lakoff, G. y M. Johnson (1980). Metaphors we Live by. Chicago: Chicago University Press.

Langacker, R. W. (1987). Foundations of Cognitive Grammar. Stanford: Stanford University Press.

Langacker, R. W. (1991). Concept, Image and Symbol: The Cognitive Basis of Grammar. Berlin: Mouton.

Lyons, J. (1981). Language and Linguistics. Cambridge: Cambridge University Press.

Rey, A. (1995). Essays on Terminology. Amsterdam: John Benjamins.

Rorty, R. (1989). Contigency, Irony and Solidarity. Cambridge: Cambridge University Press.

Recibido: 25 de junio de 2015

Aceptado: 2 de julio de 2016

Publicado: 23 de septiembre de 2016 